\title{
The Impact of Trends in the Large Scale Atmospheric Circulation on Mediterranean Surface Turbulent Heat Fluxes
}

\author{
Joy Romanski ${ }^{1}$ and Sultan Hameed ${ }^{2}$ \\ ${ }^{1}$ Columbia University, Center for Climate Systems Research, 2880 Broadway, Room 668, New York, NY 10025, USA \\ ${ }^{2}$ School of Marine and Atmospheric Sciences, State University of New York, Stony Brook, NY 11794-5000, USA
}

Correspondence should be addressed to Joy Romanski; jr988@columbia.edu

Received 13 February 2015; Accepted 3 April 2015

Academic Editor: Yafei Wang

Copyright ( 2015 J. Romanski and S. Hameed. This is an open access article distributed under the Creative Commons Attribution License, which permits unrestricted use, distribution, and reproduction in any medium, provided the original work is properly cited.

\begin{abstract}
Interannual variations of latent heat fluxes (LHF) and sensible heat fluxes (SHF) over the Mediterranean for the boreal winter season (DJF) show positive trends during 1958-2011. Using reanalysis and satellite-based products, the variability and trends in the heat fluxes are compared with variations in three atmospheric teleconnection patterns: the North Atlantic Oscillation (NAO), the pressure and position of the Azores High (AH), and the East Atlantic-West Russia teleconnection pattern (EAWR). Comparison of correlations between the heat fluxes and teleconnections, along with analysis of composites of surface temperature, humidity, and wind fields for different teleconnection states, demonstrates that the AH explains the heat flux changes more successfully than NAO and EAWR. Trends in pressure and longitude of the Azores High show a strengthening and an eastward shift. Variations of the Azores High occur along an axis defined by lower pressure and westward location at one extreme and higher pressure and eastward location at the other extreme. The shift of the AH from predominance of the low/west state to the high/east state induces trends in Mediterranean Sea surface winds, temperature, and moisture. These, combined with sea surface warming trends, produce trends in wintertime sensible and latent heat fluxes.
\end{abstract}

\section{Introduction}

Low-frequency variability of the large scale atmospheric circulation over the North Atlantic and Europe has long been recognized as a critical driver of climate variability in the region. As early as 1939, [1] used averages of daily surface pressure observations to identify several large scale circulation features. They called these structures the "semipermanent centers of action." These included the Icelandic and Aleutian Lows, the Azores High, the Hawaiian High, and the Siberia High (Icelandic Low and Azores High can be seen in Figure 1). The authors suggested that there was a relationship between the displacement of the Aleutian Low and the intensity of the zonal circulation in the North Pacific. In the northern hemisphere the low pressure centers drive counterclockwise winds around them, while the winds associated with the highs are clockwise. The winds associated with a center of action dominate atmospheric circulation in that domain. In general, the centers of action exist within spatially inhomogeneous environments that are characterized by latitudinal and longitudinal gradients of temperature and humidity. The properties of the air masses advected by the winds induced by the centers of action depend on the position of the center of action with respect to the larger scale gradients. It follows that fluctuations in the pressures and positions of the atmospheric pressure centers produce changes in surface wind speed and direction, and these, in turn, change temperature and humidity, thereby altering fluxes of heat and moisture.

Many studies describe atmospheric pressure center variability and its role in regional climate. A widely used method of studying atmospheric circulation variability is the identification of commonly occurring large scale patterns in climate variables related to circulation, such as sea level pressure (SLP, see Abbreviations for definition of this and other acronyms), or geopotential height. Several such modes of variability have been identified, the most important being the North Atlantic Oscillation (NAO), a meridional redistribution of 


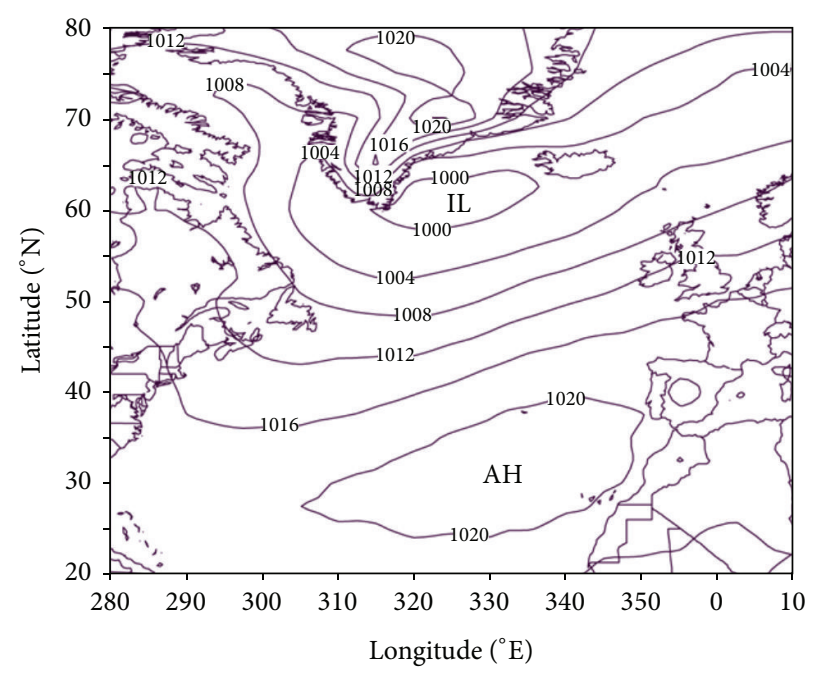

Figure 1: DJF mean SLP over the North Atlantic, 1971-2000.

atmospheric mass with centers of action near Iceland and the Azores (e.g., [2, 3]). Other patterns have also been recognized, such as the East Atlantic pattern $[2,4]$, the Scandinavian pattern [4], the North Caspian pattern [5], and the East Atlantic West Russia pattern $[4,6]$.

Several methods are used to characterize atmospheric circulation variability modes. One is the station-based approach, where the difference between normalized SLP at two stations chosen to represent the centers of action of the teleconnection is taken to represent time variability of the teleconnection (e.g., $[3,5])$. This approach does not account for the extended structure of the Icelandic Low and Azores High nor for fluctuations in their shapes and locations, which induce corresponding changes in the distribution of wind stress on the ocean surface [7]. Nevertheless, it is widely used in studies relating climate variables to teleconnection activity ([8] and references therein). Another method is to identify patterns by means of empirical orthogonal function (EOF) analysis, in which the leading eigenvectors of the covariance matrix of SLP or geopotential height are taken to represent different teleconnection patterns, and their corresponding principal components represent the loading, or importance, of that pattern as a function of time (e.g., $[4,9,10])$.

The location of the centers of action of wintertime North Atlantic teleconnection patterns has been shown to exhibit large interdecadal variability over the previous century [11, 12]. These studies found that the location of the centers of action was linked to the phase of the NAO, with eastward displacement associated with the positive phase of the NAO (i.e., a larger meridional pressure difference). This pattern dominated during the 1930s-1950s [12]. The linkage between $\mathrm{NAO}+$ and eastward displacement is especially strong for the anticyclonic center of action near the Azores [12]. In more recent decades, several researchers found a shift toward more frequent occurrence of the NAO+/eastward Azores High combination since the late 1970s [9, 13-15].

The Mediterranean was identified as an area likely to undergo large changes in the coming decades in response to anthropogenic forcing [16]. The region is expected to experience increasing SST, increasing evaporation, and decreasing precipitation, significantly altering the energy and freshwater budgets of the Mediterranean Sea [17]. To understand the predicted changes, it is critical to understand and characterize Mediterranean water cycle variability in recent decades [17].

Many studies examined the influence of atmospheric teleconnections on the climate of the Mediterranean. The paper [18] compared the impact of the North Caspian Pattern (NCP) and the NAO on air-sea heat fluxes and found that the NCP affects air-sea heat fluxes in the eastern Mediterranean, while the NAO is more important in the western Mediterranean. In contrast, [19] considered the NAO, East AtlanticWest Russia (EAWR), and East Atlantic (EA) patterns and found a much smaller role for the NAO compared to the EA and EAWR. The paper [19] demonstrated a strong basin-wide response of net heat flux to the EA and a spatially varying response to the EAWR, with approximately equal and opposite signs between the eastern and western halves of the basin. The paper [20] showed that both the NCP and NAO affect turbulent heat fluxes in the central and eastern Mediterranean by modulating the frequency and location of cyclones. The basin-wide response of turbulent heat fluxes to the EA was also noted by [21]; however, they did not find any association between subbasin scale fluxes and any of the indices.

Different indices were associated with precipitation in different parts of the Mediterranean basin by $[6,22]$, who found that the NAO influenced precipitation in the western central Mediterranean, whereas the EAWR was more important in the eastern Mediterranean. They suggested that the NAO and EAWR interact, proposing the possibility that a positive NAO may increase the likelihood of a positive EAWR. The paper [23] related the NAO and EAWR individually and in combination to the frequency of occurrence of distinct patterns of Mediterranean precipitation, finding a pattern of reduced precipitation in the central Mediterranean and enhanced precipitation in the eastern Mediterranean that is most likely to occur when both the NAO and EAWR are positive. 
Teleconnections were shown to influence SST as well. The paper [24] found that the EA is correlated with SST over the entire basin. According to [24], the NAO has the strongest influence in the western and central Mediterranean, while [25] showed that the NAO and EAWR affect SSTs in the eastern Mediterranean and Black Seas. Mediterranean Sea level [26] and wave height were shown to be anticorrelated with the $\mathrm{NAO}$, although mesoscale storminess, land-sea orientation, and local orography were found to modify the influence of the large scale atmospheric structure on wave height [27].

Atmospheric circulation variability can have large impacts on the water mass structure of the Mediterranean. Wintertime temperature, wind, and precipitation are all influenced by teleconnection patterns (e.g., $[6,19,25])$. These in turn alter the thermohaline circulation $[28,29]$ via changes to surface heat fluxes, wind forcing, and salinity [30, 31]. The influence on the water mass characteristics extends through the entire Mediterranean and may persist for many years [32].

The recent focus on relationships between large scale atmospheric teleconnections and various climate parameters in the Mediterranean region revealed that the western and central Mediterranean tends to vary out of phase with the eastern Mediterranean, with the NAO generally associated with variability in the western and central Mediterranean, either directly or indirectly via another oscillation, and the EAWR or NCP patterns having greater influence over the eastern Mediterranean, although the findings are not consistent for this region.

In light of the spatial variability of the centers of action in the North Atlantic discussed above, we chose the centers of action (COA) approach for characterizing the atmospheric circulation structure and variability. This method permits us to identify the intensity and spatial position of the Icelandic Low and Azores High (see Section 2), allowing characterization of atmospheric circulation variability and its effect on regional climate, in a more physically meaningful way. As it does not rely on fixed stations or patterns, it is well suited for exploring the regional effects of fluctuations in the location, as well as the intensity, of atmospheric pressure centers.

Recently, the COA approach was used to investigate several regional phenomena. The paper [33] showed that the interannual variability of Gulf Stream north wall position has higher correlation with the longitude of the Icelandic Low than with the NAO. The paper [34] investigated the relationship between summer precipitation over the Sahel and the Azores High. The results showed that the longitudinal displacement of the Azores High has a significant impact on interannual variation as well as decadal trends in Sahel rainfall. When the Azores High is displaced westwards, the Sahel experiences more precipitation, and in summers when the Azores High shifts eastwards, precipitation in the Sahel region is reduced. The paper [35] found that decreasing trends in wind speed and rates of ocean upwelling in the southern Caribbean Sea are related to a northward shift of the Azores High.

The Mediterranean is a concentration basin, where warmer, fresher surface water inflow from the Atlantic is modified via latent and sensible heat exchanges with the atmosphere, becoming colder, saltier, and denser before exiting at depth through Gibraltar (e.g., $[36,37])$. This water mass, known as Mediterranean Outflow Water, plays an important role in regulating the strength and stability of the Atlantic Meridional Overturning Circulation, a major component of the global thermohaline circulation [38, 39]. Several studies demonstrated warming and salinification of Mediterranean outflow over the past several decades [37, 39-41]. These changes were attributed to a combination of causes, including damming of the Nile, changes in the properties of Atlantic inflow waters, and trends in turbulent heat fluxes [40]. Sensitivity studies using climate models suggested that increasing Mediterranean outflow salinity stabilizes the Atlantic overturning circulation, especially in conditions where deep water formation in the North Atlantic is weak [38]. Hence, trends in Mediterranean Sea turbulent heat fluxes may play a vital role in maintaining the global overturning circulation as high latitude waters freshen [39].

The Mediterranean Sea is located just to the east of the mean location of the Azores High (see Figure 1). Accordingly, changes in the intensity and location of the Azores High alter the wind strength and direction over the Mediterranean and thereby have a large influence on the climate of the region. This study relates trends in Mediterranean latent and sensible heat fluxes to trends in the intensity and eastward displacement of the Azores High, via their influence on winds and air-sea gradients of temperature and humidity. Section 2 describes the methodology used in identifying the centers of action and the datasets used herein; Section 3 describes trends in boreal winter (December, January, February (DJF)) Mediterranean Sea latent and sensible heat fluxes from 1958 to 2011, presents trends in the NAO, EAWR, and Azores High pressure, latitude, and longitude, discusses covariability of Azores High intensity and longitude, and attributes trends in latent and sensible heat to changes in wind speed and airsea gradients of temperature and humidity, which are then related to changes in Azores High pressure and longitude. Section 4 discusses these findings in the context of observed and predicted changes of large scale atmospheric circulation.

\section{Methodology and Data}

To quantify the changes in the centers of action, objective indices for the pressure, latitude, and longitude locations for the centers are calculated using gridded SLP data [42]. By examining the monthly SLP maps of the past one hundred years, the latitude-longitude domains over which each of the pressure centers occurs were identified. The pressure index is then defined as an area-weighted pressure departure from a threshold value over the domain $(i, j)$ :

$$
I_{P}=\frac{\sum_{i j=1}^{I J}\left(P_{i j}-P_{t}\right) \cos \phi_{i j}(-1)^{M} \delta_{i j}}{\sum_{i j=1}^{I J} \cos \phi_{i j} \delta_{i j}},
$$

where $P_{i j}$ is the SLP value at grid point $(i, j), P_{t}$ is the threshold SLP value $\left(P_{t}=1014 \mathrm{mb}\right.$ for Azores High and Icelandic Low $)$, and $\phi_{i j}$ is the latitude of grid point $(i, j) . M=0$ for the Azores High and 1 for the Icelandic Low. $\delta=1$ if $(-1)^{M}\left(P_{i j}-P_{t}\right)>0$ and $\delta=0$ if $(-1)^{M}\left(P_{i j}-P_{t}\right)<0$. The pressure index is thus a 
measure of the anomaly of atmospheric mass over the study sector $(i, j)$. The latitudinal index is defined as

$$
I_{\phi}=\frac{\sum_{i j=1}^{I J}\left(P_{i j}-P_{t}\right) \phi_{i j} \cos \phi_{i j}(-1)^{M} \delta_{i j}}{\sum_{i j=1}^{I J}\left(P_{i j}-P_{t}\right) \cos \phi_{i j}(-1)^{M} \delta_{i j}}
$$

and the longitudinal index $I_{l}$ is defined in an analogous manner. The location indices thus give pressure-weighted mean latitudinal and longitudinal positions of the centers.

The area domains covered by the indices are the Icelandic Low $\left(40^{\circ} \mathrm{N}-75^{\circ} \mathrm{N}, 90^{\circ} \mathrm{W}-20^{\circ} \mathrm{E}\right)$ and the Azores High $\left(20^{\circ} \mathrm{N}-\right.$ $\left.50^{\circ} \mathrm{N}, 70^{\circ} \mathrm{W}-10^{\circ} \mathrm{E}\right)$. Monthly sea level pressure data from the National Center for Atmospheric Research (NCAR) (http://rda.ucar.edu/datasets/ds010.1/) [43] were used in calculating the indices using the method described in [42]. Note that the domains of the two pressure centers overlap because the two centers migrate back and forth over the North Atlantic; however, there is no overlap in calculating their indices because, for a given month, only those grid points where the SLP exceeds the threshold value $P_{t}$ are counted for the Azores High, and those for which the SLP is less than $P_{t}$ are counted for the Icelandic Low. The indices of the Icelandic Low and the Azores High were recently used to investigate the interannual variations of the Gulf Stream north wall [33] and the variations of zooplankton in the Gulf of Maine [44].

The monthly mean NAO index used here is from the National Oceanic and Atmospheric Administration (NOAA)/National Weather Service Climate Prediction Center and is computed using the Rotated Principal Component Analysis method of [4]. For more information, see http:// www.cpc.ncep.noaa.gov/products/precip/CWlink/daily_ao_ index/history/method.shtml.

Monthly mean values of the EAWR index are also from the NOAA/National Weather Service Climate Prediction Center and have been computed using [4]'s procedure. Please see http://www.cpc.ncep.noaa.gov/data/teledoc/eawruss.shtml for further details.

Turbulent fluxes (latent and sensible heat, referred to as LHF and SHF, resp.) and the quantities they are derived from (wind speed, near surface air temperature and humidity, and SST) are from the Objectively Analyzed Air-Sea Flux (OAFlux) merged satellite and reanalysis product [45] produced by the Woods Hole Oceanographic Institution (WHOI). For this study, specific humidity at the sea surface is computed from SST assuming saturation using the Coupled Ocean Atmosphere Response Experiment (COARE) v2.5b algorithm, available at http://woodshole.er.usgs.gov/operations/sea-mat/air_sea-html/qsat.html. OAFlux data are derived by synthesizing satellite-based observations with output from several reanalyses using an objective analysis algorithm that minimizes error with respect to independent surfacebased observations. OAFlux heat fluxes agree with the shipbased National Oceanography Centre climatology [46] and are on average within 5\% of buoy-ship flux measurements with no bias [45]. They are monthly means at $1^{\circ}$ resolution.

Because OAFlux provides wind speed but not $u$ and $v$ winds, we take daily mean $10 \mathrm{~m} u$ and $v$ winds from the National Center for Environmental Prediction/National
Center for Atmospheric Research (NCEP/NCAR) Reanalysis I [47]. The NCEP/NCAR Reanalysis assimilates a wide variety of input data (e.g., land surface, ship, rawinsonde, aircraft, satellite, and other observations) into an analysis/forecast atmospheric model, designed to produce a quality-controlled record of atmospheric quantities which is consistent with available observations but does not exhibit variations due to changes in observing system and is temporally and spatially complete. Quantities are classified according to how much they rely on model predictions as compared to observations. $u$ and $v$ winds are given the "A" classification, meaning they are in the category with the largest influence from observations. They are provided on a T62 $(192 \times 94)$ gaussian grid.

\section{Results/Discussion}

(a) Trends in Mediterranean Sea Turbulent Heat Fluxes. Figure 2 shows linear trends in LHF and SHF for DJF from 1958 to 2011. Significance of the trends is computed using the $t$-statistic, and only trends with $P$ values less than 0.05 are shown. Comparison of Figures 2(a) and 2(b) reveals that the spatial patterns of LHF and SHF trends are very similar, but the LHF trends are several times larger than the SHF trends. Values are positive everywhere, in agreement with positive trends in western, central, and eastern basin mean annual mean evaporation identified by [48] using a different satellitebased dataset. While we find positive trends in the western, central, and eastern Mediterranean basins, we observe that the eastern Mediterranean is characterized by larger spatial variability, with some areas experiencing very small trends.

The spatial pattern of LHF and SHF trends has a more complex structure than the east-west dipole often observed in the Mediterranean (see Section 1). Large trends occur in several locations along the northern shores of the Mediterranean, especially in the Gulf of Lions and the Gulf of Genoa, the Alboran Sea, the southeastern Adriatic Sea, and the northern Aegean Sea and along the southern coast of Turkey. Large trends are also found in the central Mediterranean from southern Italy southward to the North African coast and in the southern Levantine basin. Minima are found in the central Algerian basin, the central Tyrrhenian and Ionian basins, the Cretan Sea, and especially the northern Levantine basin. The paper [17] found a similar spatial distribution of trends in evaporation for October-March, 1979-2006. The main differences between the longer term, DJF trends shown here, and those described by [17] are that [17] found a smaller trend in the central Mediterranean and a larger trend in the northern Levantine basin. While [17, 49] did not present spatial patterns of evaporation trends prior to 1979, they found a negative trend in Mediterranean-mean evaporation during the 1960s and early 1970s, with the sign of the trend becoming positive after 1975, and stated that the eastern and western Mediterranean basin means exhibit the same trends as the Mediterranean as a whole. Small positive, but significant, trends were found for Mediterranean mean evaporation from 1958 to 2006, whereas 1979-2006 trends are much larger [17]. The good agreement between the spatial distribution shown by [17] and that shown here suggests that the spatial pattern of 


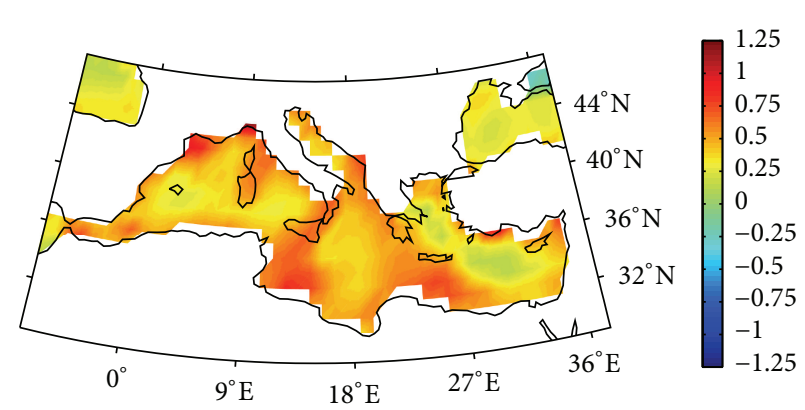

(a)

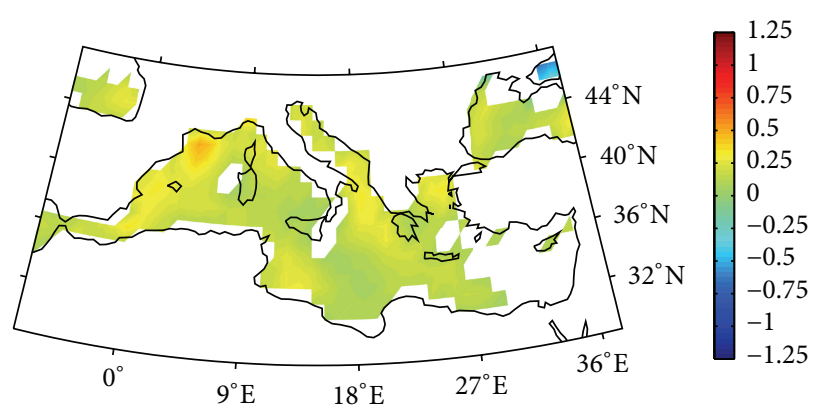

(b)

Figure 2: (a) Trends in DJF mean latent heat flux, 1958-2011 ( $\left.\mathrm{Wm}^{-2} / \mathrm{yr}\right)$; (b) trends in DJF mean sensible heat flux, 1958-2011 (Wm ${ }^{-2} / \mathrm{yr}$ ). Only trends which are significant at $P=0.05$ are shown.

evaporation trends during 1979-2006 is typical of the spatial pattern of the longer trend shown here and that the large increase in evaporation during the latter period is sufficient to overcome the negative trend during the early part of the record, yielding smaller, but still positive, significant trends for the full period throughout the Mediterranean.

(b) Trends in Atmospheric Circulation Patterns. To assess the contributions of trends in the large scale atmospheric circulation to the observed trends in Mediterranean Sea winter LHF and SHF, we begin by comparing the temporal evolution of patterns known to influence the Mediterranean region. Monthly mean DJF Azores High pressure and longitude indices (definitions in Section 2) from 1958 to 2011 are shown in Figures 3(a) and 3(c). Azores High latitude does not have a significant trend during DJF for this time period (not shown). The monthly mean DJF NAO index is pictured in Figure 3(b), and the monthly mean EAWR index is shown in Figure 3(d). Linear trends are plotted if they are significant at $P=0.05$. While significant linear trends are found in the Azores High pressure and longitude and in the NAO index, the long term variation of these indices is not quite linear. In particular, the Azores High pressure and the NAO index both display the well-known leveling off during the 2000s. Our findings agree with numerous results in the literature showing a positive trend in the NAO index (e.g., $[9,11,15])$. Of course, it is not surprising that the time series of Azores High pressure and the NAO index are so similar, since the NAO index represents the strength of the difference between the Azores High and the Icelandic Low. Our identification of an eastward trend in the location of the Azores High agrees with observations by $[11-13,15,50]$ of a shift in the anticyclonic center of action located near the Azores. The paper [50] also noted an increase in SLP over the Mediterranean from about 1960 onward.

The EAWR index does not show a significant trend for the time period, in agreement with [19]. The paper [6] identified a positive trend in the October-March EAWR index from 1950 to 2000, but the trend became nonsignificant when the time series was extended beyond 2000. Thus, while the EAWR strongly affects the eastern Mediterranean on interannual time scales (see discussion in Section 1), it is not likely to be responsible for the observed trends in LHF and SHF.
While [19] showed that the October-March EA has a trend over the latter half of the 20th century, the spatial pattern of heat flux they associated with a unit change in the EA does not match the patterns shown in Figure 2, suggesting that the EA is also not responsible for the trends in LHF and SHF.

Correlation coefficients between detrended monthly mean LHF and detrended monthly mean Azores High pressure, Azores High longitude, and the NAO index are shown in Figures 4(a), 4(c), and 4(e). Figures 4(b), 4(d), and 4(f) show correlation coefficients between detrended monthly mean SHF and detrended monthly mean Azores High sea level pressure, Azores High longitude, and the NAO index. Only correlation coefficients which are significant at $P=0.05$ are shown. Correlations between LHF or SHF and Azores High pressure are similar in both pattern and magnitude to correlations between LHF or SHF fluxes and the NAO, which is to be expected given that Azores High pressure is a component of the NAO. In both instances, correlations increase along a northwest to southeast gradient, with minimum correlations in the Gulf of Lions of about -0.2 for LHF and -0.3 for SHF and maximum correlations along the southern Levantine coast of about 0.2 for LHF and 0.3 for SHF. Stronger positive correlations are found for LHF or SHF and Azores High longitude. Correlations range from about 0.1 in the northwest Mediterranean to as much as 0.4 in the Levantine basin. The correlations between LHF or SHF and Azores High longitude indicate that changes in the location of the Azores High contribute to variability of Mediterranean LHF and SHF. Thus, taken together, Azores high pressure and longitude variability can better account for LHF and SHF variability than the NAO index, which does not consider changes in location of the semipermanent centers of action.

Close examination of Figures 3(a) and 3(c) suggests that an increase in Azores High pressure accompanies an eastward displacement, while a decrease in pressure accompanies a westward displacement. To more clearly show the covariability between Azores High pressure and longitude, a scatterplot of these quantities is shown in Figure 5. While there is a lot of scatter and a few outliers, Figure 5 shows that Azores High pressure and longitude tend to fall along a low/west to high/east axis. Our finding that more intense Azores Highs occur further to the east agrees with the observed relationship 


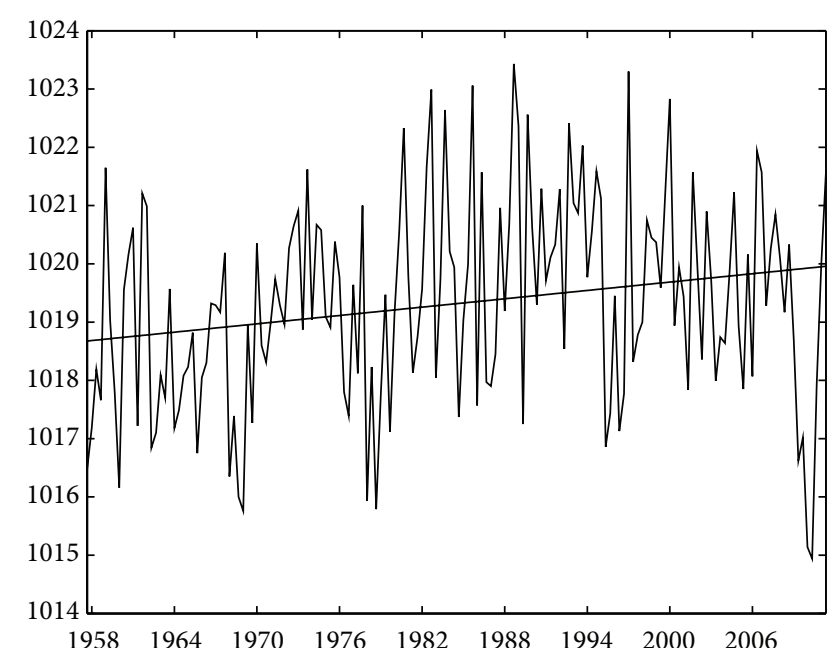

(a)

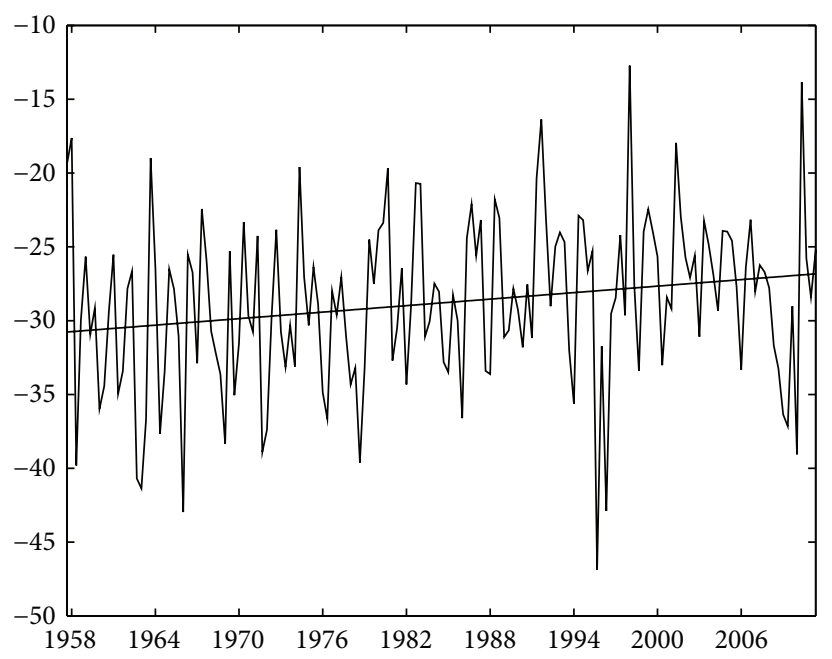

(c)

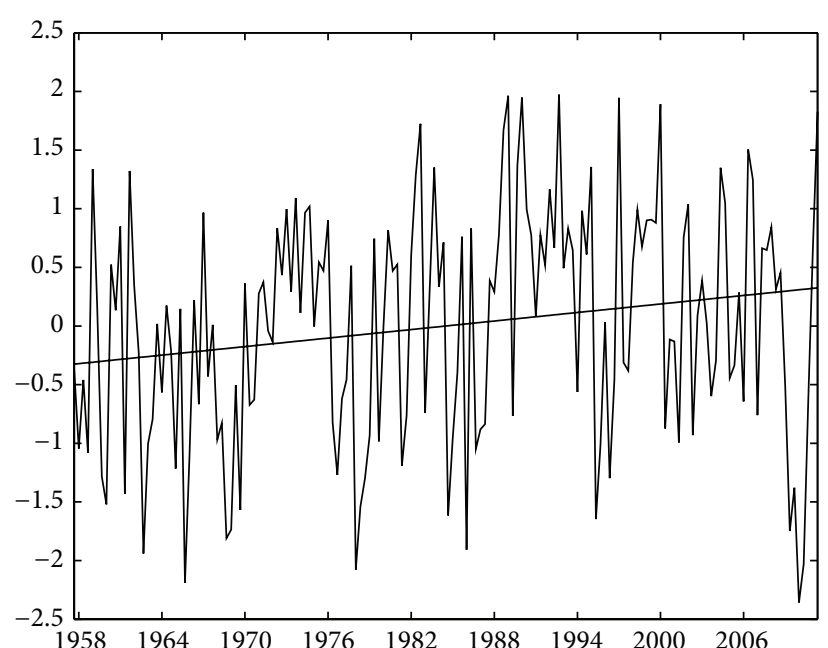

(b)

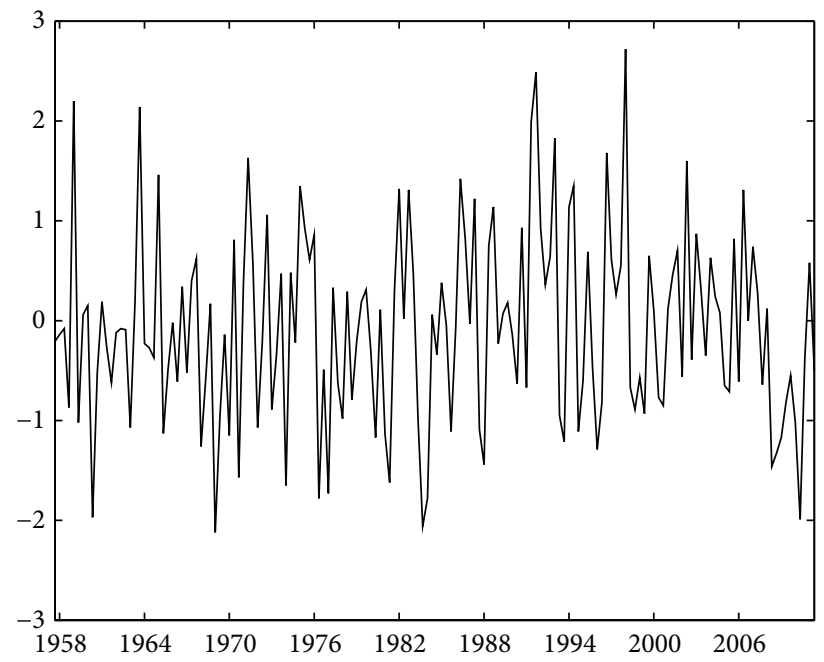

(d)

Figure 3: (a) Monthly mean Azores High sea level pressure and trend (mb), DJF 1958-2011; (b) monthly mean NAO index and trend, DJF 1958-2011; (c) monthly mean Azores High longitude (degrees east) and trend, DJF 1958-2011; (d) monthly mean EAWR index, DJF 1958-2011. Only trends which are significant at $P=0.05$ are shown.

between the NAO positive phase, characterized by a larger meridional pressure gradient, and an eastward shift of its southern center of action, the Azores High (e.g., $[9,11,15]$ ), and points to variability of the Azores High as the underlying mechanism. This, together with the trends shown in Figures 3(a) and 3(c), suggests that there has been a shift toward more frequent occurrence of the high/east state over the study period, in agreement with other studies $[11,15]$.

(c) Effect of Change of Frequency of AH States on Air-Sea Gradients, Wind Speed. To investigate the effect of a shift toward more frequent occurrence of the Azores High high/ east state on Mediterranean Sea turbulent heat fluxes, we computed composites of the air-sea gradients of humidity and temperature, as well as zonal and meridional wind velocity, for months during DJF 1958-2011 when the Azores High was simultaneously anomalously strong and eastward and for months when it was simultaneously anomalously weak and westward. We then subtracted the low/west composite from the high/east composite, yielding the spatial pattern of changes in air-sea gradients, zonal and meridional wind velocity that is induced by a shift from low/west to high/east. These are shown in Figures 6(a), 6(c), 6(e), and 6(g). LHF and SHF are computed as functions of air-sea humidity and temperature gradients scaled by wind speed and a height and stability dependent turbulent exchange coefficient [45]. Wind speed is a scalar comprising the resultant of the zonal and meridional wind velocities. Zonal and meridional velocities are defined such that positive values of zonal wind velocity indicate westerly wind components, negative values of zonal wind indicate easterly wind components, positive values of meridional velocity indicate southerly wind components, 


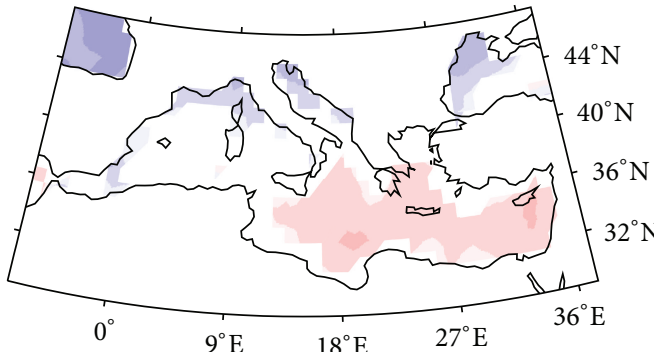

(a)

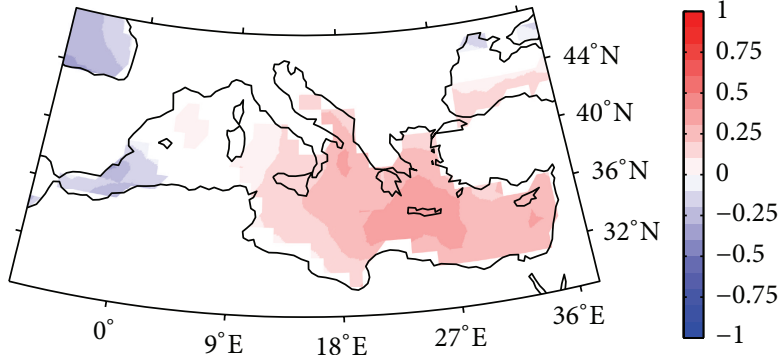

(c)

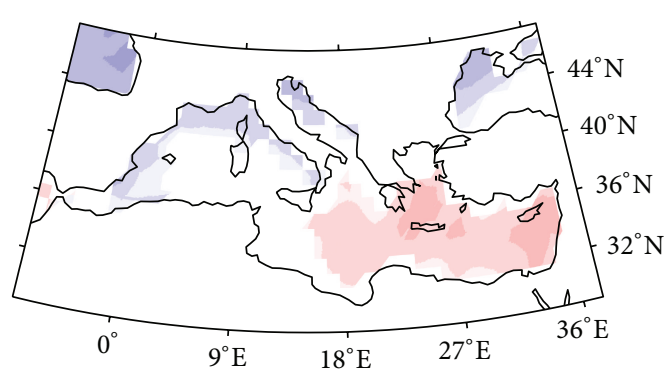

(e)

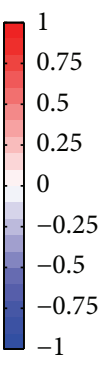

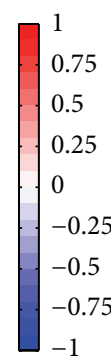

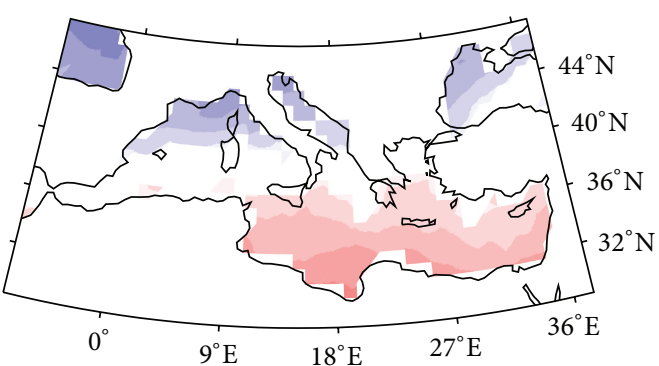

(b)

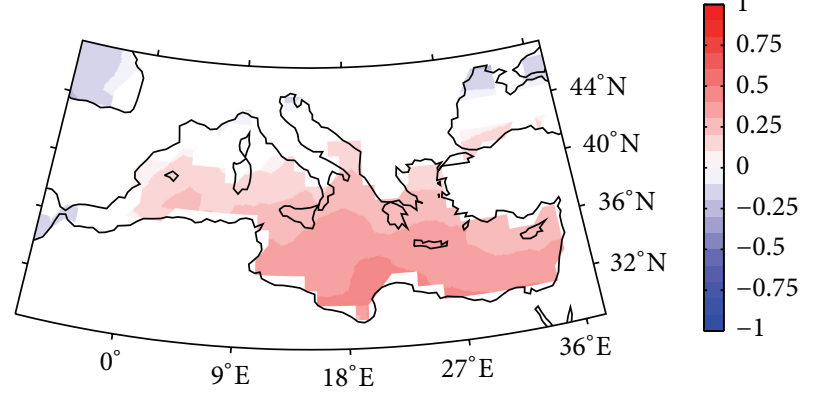

(d)

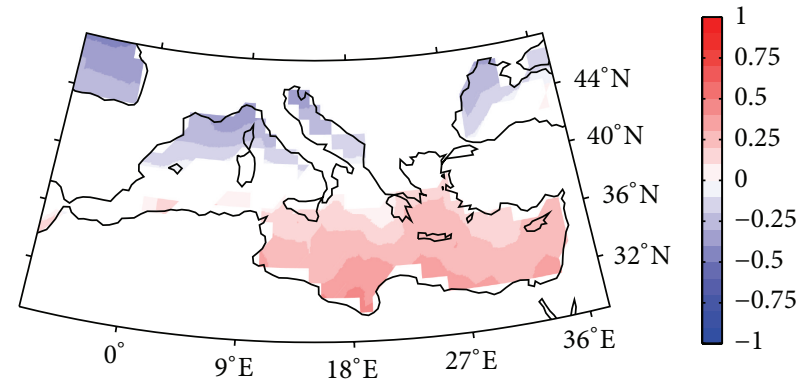

(f)

Figure 4: (a), (c), and (e) Correlations between detrended monthly mean latent heat flux and detrended Azores High sea level pressure, Azores High longitude, and NAO index; (b), (d), and (f) correlations between detrended monthly mean sensible heat flux and detrended Azores High sea level pressure, Azores High longitude, and NAO index, DJF 1958-2011. Only correlations which are significant at $P=0.05$ are shown.

and negative values of meridional velocity indicate northerly wind components. Examining the composites of wind velocity and air-sea gradients individually permits us to diagnose contributions from each to the observed flux trends. We also show composites computed for the difference between NAO+ months and NAO- months (Figures 6(b), 6(d), 6(f), and 6(h)). Significance of the difference between Azores High high/east and low/west and of the difference between NAO+ and NAO- was computed using the $t$-statistic, and only differences significant at $P=0.05$ are shown.

Figures 6(a), 6(e), and 6(g), taken together, show how the shift toward more dominant Azores High high/east conditions affects LHF via altering the air-sea humidity gradient (Figure 6(a)) and zonal and meridional wind velocity (Figures 6(e) and 6(g)). The Azores High high/east state produces larger air-sea humidity gradients everywhere, but especially in the Alboran Sea and the Ionian and Levantine basins. This pattern would tend to increase LHF everywhere but when scaled by the Azores High high/east-related zonal and meridional wind velocity changes shown in Figures 6(e) and $6(\mathrm{~g})$ produces a spatial pattern similar to the LHF trends shown in Figure 2. In particular, the meridional wind velocity difference map displays the pattern of enhanced northerly wind components near the northern coasts and in the Ionian and Levantine basins. While the meridional wind velocity composite difference shows smaller increases in the northern coastal areas, orography may locally modify and intensify winds generated by the large scale atmospheric pressure centers, as described by [27]. Even with little or no change in air-sea humidity and temperature, local wind changes could produce larger trends in LHF and SHF immediately adjacent to the northern coasts, as displayed in Figure 2. The air-sea temperature gradient difference map (Figure 6(c)), when scaled by the wind velocity differences, produces a 


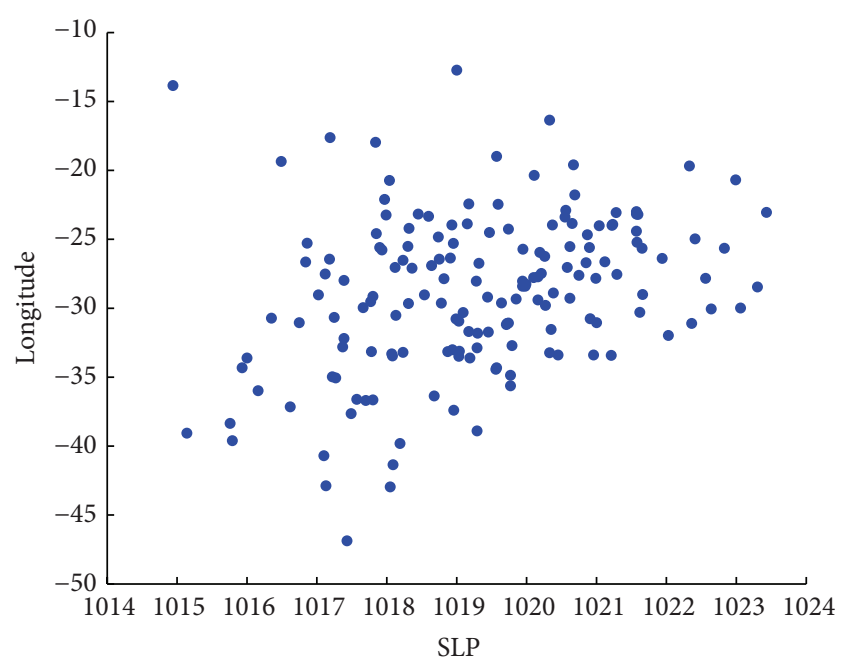

FIgURE 5: Monthly mean Azores High pressure (mb) and longitude (degrees east) for DJF 1958-2011.

pattern that resembles the SHF trends in Figure 2(b) in the central Mediterranean but does not agree with that in the northwestern Mediterranean and in the eastern Levantine basin. In the northwestern Mediterranean, increases in meridional wind velocity associated with more frequent occurrence of the Azores High high/east state could produce the SHF trend shown in Figure 2(b). Trends in SHF are not significant in the eastern Levantine basin, despite larger airsea temperature gradients and stronger northerly winds in association with more frequent Azores High high/east states. Examining Figures 2(b), 6(c), and 6(f) reveals that even in regions with the largest air-sea temperature differences and the most northerly winds (e.g., the southern Adriatic and Aegean Seas) SHF trends are fairly small, on the order of $0.25 \mathrm{Wm}^{-2} / \mathrm{yr}$. It may be that the smaller enhancement of air-sea temperature gradients and northerly wind velocities in the eastern Levantine basin under Azores High high/east conditions does not produce SHF trends that are sufficiently large to overcome interannual variability, leading to the finding of nonsignificant trends in this region.

The patterns of air-sea gradients and zonal and meridional wind velocities associated with the change from NAOto NAO+, shown in Figures 6(b), 6(d), 6(f), and 6(h), are somewhat similar to those associated with Azores High variability, which is to be expected, since the intensity of the Azores High is a component of the NAO. However, the NAO difference composites reveal that a shift toward $\mathrm{NAO}+$ produces smaller enhancements of air-sea humidity and temperature gradients and that the enhancements are largely confined to the eastern Mediterranean. Wind velocity enhancements are smaller as well and do not extend to the Gulf of Lions and the northern Adriatic. The NAO difference composite air-sea temperature gradient pattern does not show the large increase around the coast of Greece seen in the Azores High difference map. This feature produces the local maximum in SHF trends in that region and further suggests that the Azores High high/east-low/west state composites better correspond to the LHF and SHF trends than the NAO positive-NAO negative composites.

The spatial patterns of the difference composites shown in Figures 6(a), 6(c), 6(e), and 6(f) do not agree perfectly with the LHF and SHF trends in Figure 2. The main discrepancy is that the difference maps exhibit larger influence of more frequent Azores High high/east states toward the eastern end of the Mediterranean. The intensification toward the east is not observed in the LHF and SHF trends. This may result from the influence of other teleconnection patterns on Mediterranean turbulent fluxes (e.g., [19]). Nevertheless, the correspondence between LHF and SHF trends, and the spatial patterns of air-sea gradients and wind speed associated with the change in state of the Azores High from low/west to high/east, suggests that there is a strong relationship between the trends in state of the Azores High and trends in Mediterranean Sea turbulent heat fluxes.

To understand how the increase in frequency of the high/east Azores High state altered the air-sea gradients of humidity and temperature, we examined maps of composites of Azores High high/east-Azores High low/west near surface specific humidity (Figure 7(a)) and near surface air temperature (Figure 7(b)). Difference composites of Azores High high/east-Azores High low/west near surface wind vectors are plotted on top of the near surface humidity and temperature differences. Figures 7(a) and 7(b) show that that the Azores High high/east state produces drier conditions over the entire Mediterranean and colder conditions over the central and eastern Mediterranean, associated with enhanced northerly winds. As the Azores High strengthens and moves eastward, the anticyclonic wind field associated with it also strengthens and shifts eastward. Because the Mediterranean Sea is located just eastward of the Azores High, the longitudinal position of the Azores High has a large impact on the strength and direction of wind in different parts of the basin. This produces the wind vectors shown in Figures $7(\mathrm{a})$ and $7(\mathrm{~b})$, which demonstrate that intensification and eastward displacement of the Azores High are associated with stronger northerly winds over the entire basin, with the largest differences found over the eastern portion. These northerly winds associated with the Azores High high/east state advect drier, colder continental air over the warmer Mediterranean waters, leading to the enhanced air-sea humidity and temperature gradients shown in Figures 6(a) and 6(c).

Recent studies have found an upward trend of SST in the entire Mediterranean [17, 24, 48]. The paper [24] attributed this change to enhanced inflow of warm water from the Atlantic related to variability in the EA and the Atlantic Multidecadal Oscillation (AMO), a pattern of variability of the North Atlantic. The anomalously warm waters are advected eastward by the surface currents of the Mediterranean, eventually affecting the entire basin. We computed composites of Azores High high/east-Azores High low/west for SST and found no statistically significant differences over the Mediterranean (not shown), indicating that Azores High variability is not responsible for observed trends in Mediterranean SST. These findings, together with the results presented above, indicate that warmer SSTs related to the EA and AMO combine with colder, drier, and windier conditions 


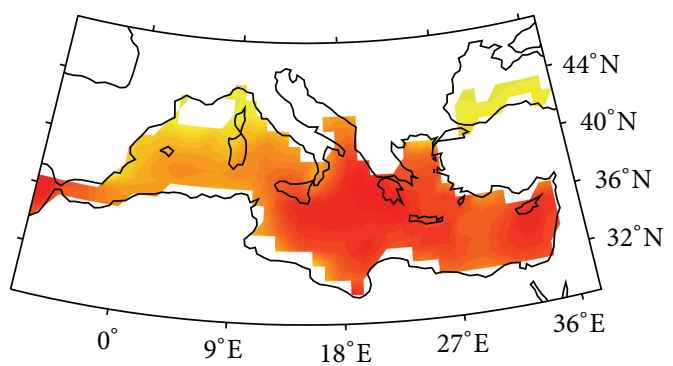

(a)

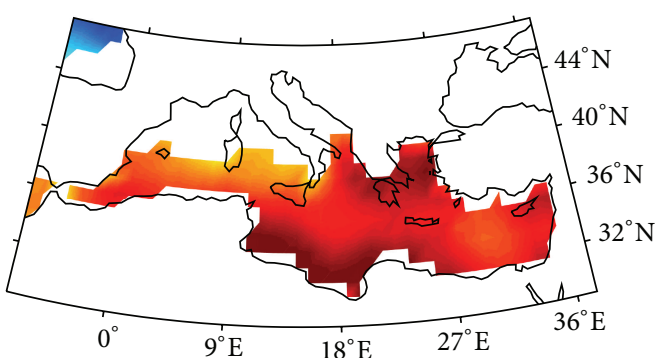

(c)

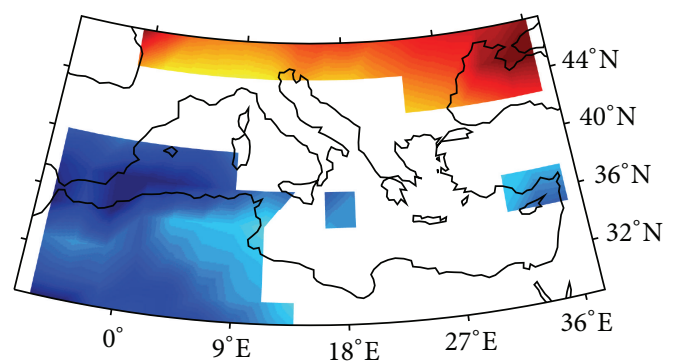

(e)

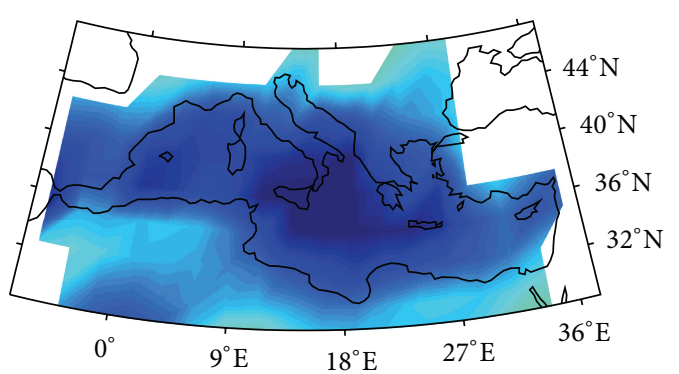

(g)
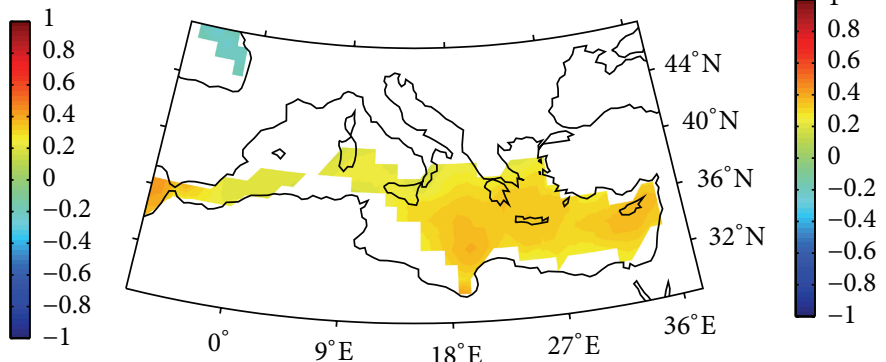

(b)
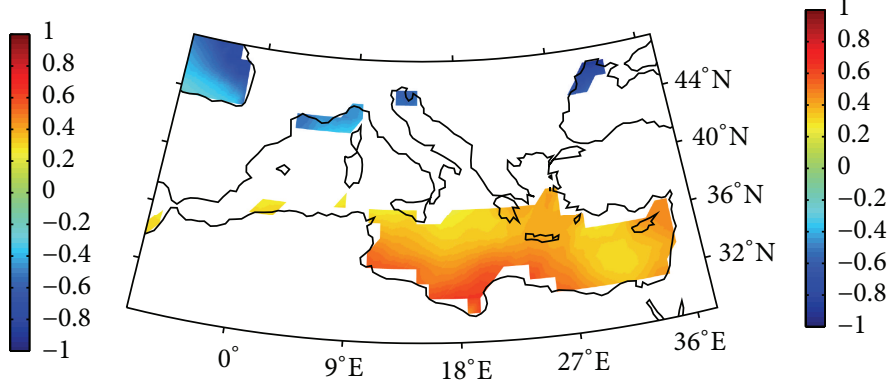

(d)
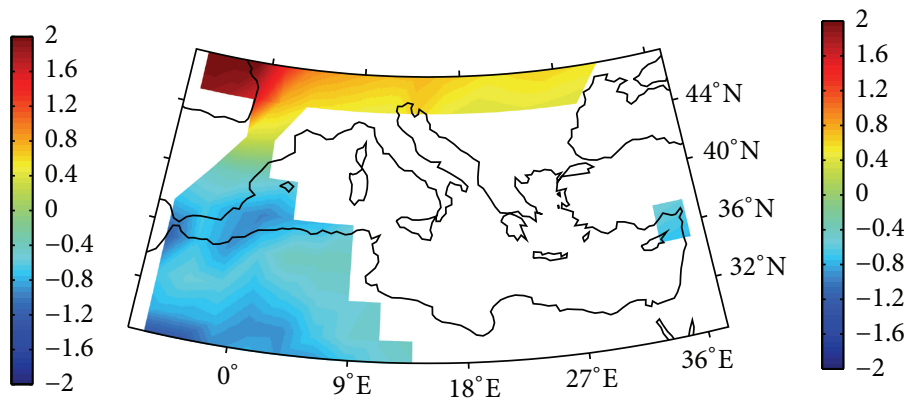

(f)
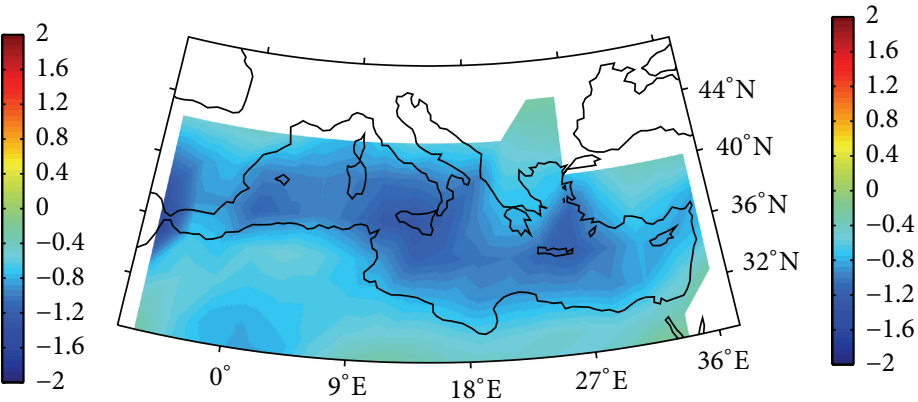

(h)

Figure 6: (a), (c), (e), and (g) AH high/east composite-AH low/west composite of monthly mean $Q_{a}-Q_{s}(\mathrm{~g} / \mathrm{kg}), T_{a}-T_{s}(\mathrm{C}), u(\mathrm{~m} / \mathrm{s})$, and $v(\mathrm{~m} / \mathrm{s})$; (b), (d), (f), and (h) NAO+ composites-NAO- composite of monthly mean $Q_{a}-Q_{s}(\mathrm{~g} / \mathrm{kg}), T_{a}-T_{s}(\mathrm{C}), u(\mathrm{~m} / \mathrm{s})$, and $v$ (m/s), DJF 1958-2011. Only differences which are significant at $P=0.05$ are shown. 


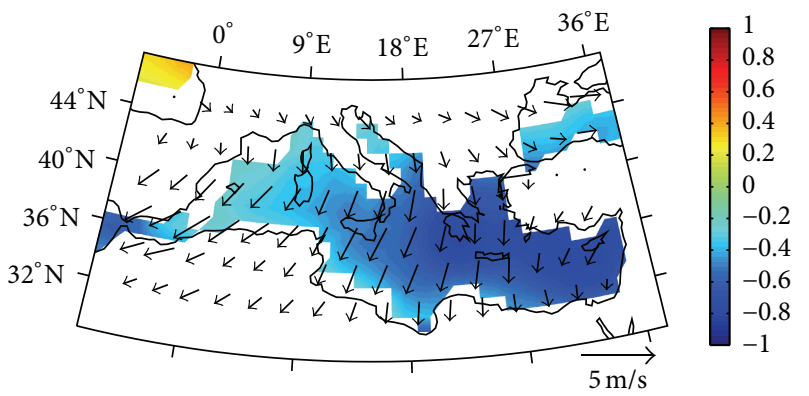

(a)

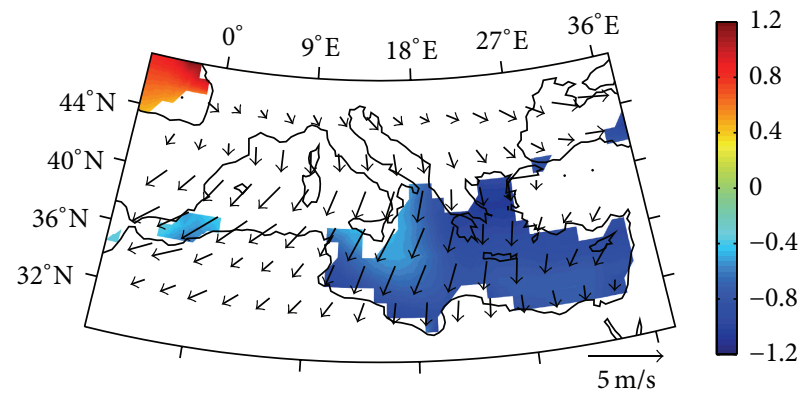

(b)

Figure 7: (a) AH high/east composite-AH low/west composite of monthly mean $Q_{a}(\mathrm{~g} / \mathrm{kg}$ ) overlaid with $\mathrm{AH}$ high/east composite-AH low/west composite of monthly mean near surface winds (m/s), DJF 1958-2011; (b) AH high/east composite-AH low/west composite of monthly mean $T_{a}(\mathrm{C})$ overlaid with AH high/east composite-AH low/west composite of monthly mean near surface winds (m/s), DJF 19582011. Only differences which are significant at $P=0.05$ are shown.

induced by more frequent Azores High high/east states, to produce the observed differences in air-sea humidity and temperature gradients, which leads to enhanced latent and sensible heat fluxes.

\section{Conclusions}

We find positive trends from 1958 to 2011 in DJF LHF and SHF over the Mediterranean. Trends are everywhere positive, in agreement with [48], but there is substantial spatial variability, particularly in LHF. Trend maxima are found near the northern coastlines, in the central Mediterranean and the southern Levantine basin. Minima occur in the central basins of the Alboran Sea in the western Mediterranean, the Tyrrhenian and Ionian Seas in the central Mediterranean, and especially the northern Levantine basin. These patterns resemble patterns in evaporation trends for a shorter time interval presented by [17], suggesting that the LHF trend spatial pattern has remained consistent over the longer time interval.

Time series of Azores High pressure and longitudinal position indices are presented, along with time series of the NAO and EAWR, two teleconnections known to influence Mediterranean climate. The Azores High indices and the NAO index are found to have a significant trend over the study period, while the EAWR has no trend. The two Azores High indices that have positive trends over the study period are found to covary such that strong Azores High pressure centers occur further to the east, while weak Azores High pressure centers are located to the west. Azores High pressure and longitude are shown to occur along a high/east to low/west axis.

The Azores High pressure and longitude axis defined by high/east to low/west and the NAO both have positive trends over the study period. To explore which mode better explains the observed trends in LHF and SHF, composites showing the effect on air-sea gradients of humidity and temperature, and on zonal and meridional wind velocities, of a shift from predominantly Azores High low/west to high/east conditions are constructed. Similar composites are also constructed for air-sea humidity and temperature gradients and zonal and meridional wind velocities associated with a shift from $\mathrm{NAO}-$ to $\mathrm{NAO}+$ conditions. Examination of the composites reveals that while the patterns are somewhat similar, as expected since the NAO index is a measure of the intensity of the pressure gradient between the Icelandic Low and the Azores High, the Azores High high/east-low/west composites of air-sea gradients and wind velocity are more similar to the LHF and SHF trends. This suggests that the additional information on spatial variability in the location of the Azores High improves understanding of the long term trends in Mediterranean Sea LHF and SHF, compared to using only the pressure difference, as in the NAO index.

Further exploration of the effect of increasing frequency of the Azores High high/east state on wind direction, near surface humidity, and temperature over the Mediterranean reveals that the eastward shift and intensification of the anticyclonic circulation around the Azores High is associated with northerly winds over most of the basin, resulting in advection of cold, dry air. The trend toward windier, colder, drier conditions combines with long term warming of the sea surface related to the EA and AMO, to enhance LHF and SHF.

Examining Mediterranean climate variability with respect to Azores High variability rather than one of the other ways of describing large scale atmospheric circulation variability that have fixed modes (e.g., indices derived from station measurements of SLP, as in [3], or principal component analysis (PCA)/EOF, as in [4]) relates it to easily observed, physically meaningful phenomena. Similar results might be obtained using another representation of the meridional pressure dipole, as it is the dominant mode of variability in the region. However, the center of action method used here is not computationally burdensome, is directly related to observed physical quantities, and is appropriate for investigating the effect of fluctuations in the location of the centers of action on regional climate. Indeed, we find that adding information on the position of the Azores High improves the outcome of our analysis.

Previous studies agree that the strength of the pressure dipole is intrinsically related to shifts in the location of the centers of action, in the past [51] and current climates $[9,11]$, 
and in model simulations of past and present climates [50, 51]. It is unclear whether this relationship will continue in the future. The paper [51] found that, in a $1 \% \mathrm{CO}_{2}$ increase scenario, simulated 21st century teleconnectivity axes continue to display the same spatial variability but become more stable in time, leading them to hypothesize that external forcing may increase the likelihood of a persistent northsouth or northwest-southeast state. The paper [52], however, found no trends in the NAO in a Representative Concentration Pathway (RCP) 8.5 scenario (i.e., large anthropogenic forcing) for the 21st century but did see continuous strengthening and eastward expansion of the Azores High.

The relationship of the Mediterranean heat fluxes with the Azores High is interesting for the additional reason that the Azores High represents the downward branch of the Hadley circulation in the North Atlantic sector. The increasing strength of the Azores High is an example of the strengthening and expansion of Hadley circulation that has been attributed to anthropogenic warming $[53,54]$. Because of large natural variability, it may not be possible to conclusively attribute late 20th century trends in North Atlantic large scale atmospheric circulation to external forcing [14, 50]. However, the anthropogenically forced changes in the Hadley circulation and subsequent changes in the strength and position of the Azores High lend support to [9]'s and [51]'s suggestion that anthropogenic climate change may manifest in the North Atlantic atmospheric circulation as changes in mode stability and variability. If the current trend in the DJF Azores High pressure continues, we can expect the trend of increasing surface heat fluxes in the Mediterranean in the future, which could have large impacts on many aspects of Mediterranean climate, including circulation, biogeochemistry, biological productivity, and hydrography [30-32, 55, 56] and on the global thermohaline circulation $[38,39]$.

\section{Abbreviations}

AMO:

Atlantic Multidecadal Oscillation

COA:

Centers of action

COARE:

Coupled Ocean Atmosphere Response

Experiment

DJF: $\quad$ December, January, and February

EA: $\quad$ East Atlantic teleconnection pattern

EAWR: $\quad$ East Atlantic-West Russia teleconnection pattern

EOF: $\quad$ Empirical orthogonal function

LHF: $\quad$ Latent heat flux

NAO: $\quad$ North Atlantic Oscillation

NCAR: National Center for Atmospheric Research

NCEP/NCAR: National Center for Environmental

Prediction/National Center for

Atmospheric Research

NCP: $\quad$ North Caspian pattern

NOAA: National Oceanic and Atmospheric

Administration

OAFlux: $\quad$ Objectively analyzed air-sea flux

PCA: $\quad$ Principal component analysis

RCP: Representative Concentration Pathway

SHF: $\quad$ Sensible heat flux
SLP: Sea level pressure

SST: $\quad$ Sea surface temperature

WHOI: Woods Hole Oceanographic Institution.

\section{Conflict of Interests}

The authors declare that there is no conflict of interests regarding the publication of this paper.

\section{References}

[1] C. Rossby, "Relation between variations in the intensity of the zonal circulation of the atmosphere and the displacements of the semi-permanent centers of action," Journal of Marine Research, vol. 2, no. 1, pp. 38-55, 1939.

[2] J. M. Wallace and D. S. Gutzler, "Teleconnections in the geopotential height field during the Northern Hemisphere winter," Monthly Weather Review, vol. 109, no. 4, pp. 784-812, 1981.

[3] J. W. Hurrell, "Decadal trends in the North Atlantic Oscillation: regional temperatures and precipitation," Science, vol. 269, no. 5224, pp. 676-679, 1995.

[4] A. G. Barnston and R. E. Livezey, "Classification, seasonality and persistence of low-frequency atmospheric circulation patterns," Monthly Weather Review, vol. 115, no. 6, pp. 1083-1126, 1987.

[5] H. Kutiel and Y. Benaroch, "North Sea-Caspian pattern (NCP) - an upper level atmospheric teleconnection affecting the Eastern Mediterranean: identification and definition," Theoretical and Applied Climatology, vol. 71, no. 1-2, pp. 17-28, 2002.

[6] S. O. Krichak and P. Alpert, "Signatures of the NAO in the atmospheric circulation during wet winter months over the Mediterranean region," Theoretical and Applied Climatology, vol. 82, no. 1-2, pp. 27-39, 2005.

[7] P. E. Lydolph, The Climate of the Earth, Government Institutes, 1985.

[8] L. Pokorná and R. Huth, "Climate impacts of the NAO are sensitive to how the NAO is defined," Theoretical and Applied Climatology, vol. 119, no. 3-4, pp. 639-652, 2015.

[9] J. W. Hurrell and C. Deser, "North Atlantic climate variability: the role of the North Atlantic Oscillation," Journal of Marine Systems, vol. 79, no. 3-4, pp. 231-244, 2010.

[10] J. W. Hurrell and H. van Loon, "Decadal variations in climate associated with the North Atlantic oscillation," Climatic Change, vol. 36, no. 3-4, pp. 301-326, 1997.

[11] C. Cassou, L. Terray, J. W. Hurrell, and C. Deser, "North Atlantic winter climate regimes: spatial asymmetry, stationarity with time, and oceanic forcing," Journal of Climate, vol. 17, no. 5, pp. 1055-1068, 2004.

[12] G. W. K. Moore, I. A. Renfrew, and R. S. Pickart, "Multidecadal mobility of the north atlantic oscillation," Journal of Climate, vol. 26, no. 8, pp. 2453-2466, 2013.

[13] E. Kostopoulou and P. D. Jones, "Comprehensive analysis of the climate variability in the eastern Mediterranean. Part I: mappattern classification," International Journal of Climatology, vol. 27, no. 9, pp. 1189-1214, 2007.

[14] T. Jung, M. Hilmer, E. Ruprecht, S. Kleppek, S. K. Gulev, and O. Zolina, "Characteristics of the recent eastward shift of interannual NAO variability," Journal of Climate, vol. 16, no. 20, pp. 3371-3382, 2003. 
[15] N. C. Johnson, S. B. Feldstein, and B. Tremblay, "The continuum of northern hemisphere teleconnection patterns and a description of the NAO shift with the use of self-organizing maps," Journal of Climate, vol. 21, no. 23, pp. 6354-6371, 2008.

[16] IPCC, Climate Change 2007: The Physical Science Basis, Contribution of Working Group I to the Fourth Assessment Report of the Intergovernmental Panel on Climate Change, Cambridge University Press, Cambridge, UK, 2007.

[17] A. Mariotti, "Recent changes in the Mediterranean water cycle: a pathway toward long-term regional hydroclimatic change?" Journal of Climate, vol. 23, no. 6, pp. 1513-1525, 2010.

[18] M. Gündüz and E. Özsoy, "Effects of the North Sea Caspian pattern on surface fluxes of Euro-Asian-Mediterranean seas," Geophysical Research Letters, vol. 32, no. 21, Article ID L21701, pp. 1-4, 2005.

[19] S. A. Josey, S. Somot, and M. Tsimplis, "Impacts of atmospheric modes of variability on Mediterranean Sea surface heat exchange," Journal of Geophysical Research, vol. 116, Article ID C02032, pp. 1-15, 2011.

[20] J. Romanski, A. Romanou, M. Bauer, and G. Tselioudis, “Teleconnections, midlatitude cyclones and Aegean Sea turbulent heat flux variability on daily through decadal time scales," Regional Environmental Change, vol. 14, no. 5, pp. 1713-1723, 2013.

[21] I. I. Zveryaev and A. A. Hannachi, "Interannual variability of Mediterranean evaporation and its relation to regional climate," Climate Dynamics, vol. 38, no. 3-4, pp. 495-512, 2012.

[22] S. O. Krichak, P. Kishcha, and P. Alpert, "Decadal trends of main Eurasian oscillations and the eastern Mediterranean precipitation," Theoretical and Applied Climatology, vol. 72, no. 3-4, pp. 209-220, 2002.

[23] E. Black, "The influence of the North Atlantic Oscillation and European circulation regimes on the daily to interannual variability of winter precipitation in Israel," International Journal of Climatology, vol. 32, no. 11, pp. 1654-1664, 2012.

[24] N. Skliris, S. Sofianos, A. Gkanasos et al., "Decadal scale variability of sea surface temperature in the Mediterranean Sea in relation to atmospheric variability," Ocean Dynamics, vol. 62, no. 1, pp. 13-30, 2012.

[25] A. S. Kazmin, A. G. Zatsepin, and H. Kontoyiannis, "Comparative analysis of the long-term variability of winter surface temperature in the Black and Aegean seas during 1982-2004 associated with the large-scale atmospheric forcing," International Journal of Climatology, vol. 30, no. 9, pp. 1349-1359, 2010.

[26] M. N. Tsimplis, F. M. Calafat, M. Marcos et al., "The effect of the NAO on sea level and on mass changes in the Mediterranean Sea," Journal of Geophysical Research C: Oceans, vol. 118, no. 2, pp. 944-952, 2013.

[27] P. Lionello and A. Sanna, "Mediterranean wave climate variability and its links with NAO and Indian Monsoon," Climate Dynamics, vol. 25, no. 6, pp. 611-623, 2005.

[28] P. Malanotte-Rizzoli, B. B. Manca, M. R. D’Alcala et al., "The Eastern Mediterranean in the 80s and in the 90s: the big transition in the intermediate and deep circulations," Dynamics of Atmospheres and Oceans, vol. 29, no. 2-4, pp. 365-395, 1999.

[29] B. Klein, W. Roether, B. B. Manca et al., "The large deep water transient in the Eastern Mediterranean," Deep-Sea Research Part I: Oceanographic Research Papers, vol. 46, no. 3, pp. 371-414, 1999.

[30] S. A. Josey, "Changes in the heat and freshwater forcing of the eastern Mediterranean and their influence on deep water formation," Journal of Geophysical Research: Oceans, vol. 108, no. C7, 2003.

[31] J. Romanski, A. Romanou, M. Bauer, and G. Tselioudis, "Atmospheric forcing of the Eastern Mediterranean Transient by midlatitude cyclones," Geophysical Research Letters, vol. 39, no. 3, p. L03703, 2012.

[32] M. Herrmann, F. Sevault, J. Beuvier, and S. Somot, "What induced the exceptional 2005 convection event in the northwestern Mediterranean basin? Answers from a modeling study," Journal of Geophysical Research, vol. 115, no. 12, Article ID C12051, 2010.

[33] S. Hameed and S. A. Piontkovski, "The dominant influence of the Icelandic Low on the position of the Gulf Stream northwall," Geophysical Research Letters, vol. 31, no. 9, Article ID L09303, 2004.

[34] S. Hameed and N. Riemer, "Relationship of Sahel precipitation and atmospheric centers of action," Advances in Meteorology, vol. 2012, Article ID 953853, 8 pages, 2012.

[35] G. T. Taylor, F. E. Muller-Karger, R. C. Thunell et al., "Ecosystem responses in the southern Caribbean Sea to global climate change," Proceedings of the National Academy of Sciences of the United States of America, vol. 109, no. 47, pp. 19315-19320, 2012.

[36] P. G. Myers and K. Haines, "Stability of the Mediterranean's thermohaline circulation under modified surface evaporative fluxs," Journal of Geophysical Research, vol. 107, no. 3, article 3021, 9 pages, 2002.

[37] C. Millot, J. Candela, J.-L. Fuda, and Y. Tber, "Large warming and salinification of the Mediterranean outflow due to changes in its composition," Deep-Sea Research Part I: Oceanographic Research Papers, vol. 53, no. 4, pp. 656-666, 2006.

[38] R. F. Ivanovic, P. J. Valdes, L. Gregoire, R. Flecker, and M. Gutjahr, "Sensitivity of modern climate to the presence, strength and salinity of Mediterranean-Atlantic exchange in a global general circulation model," Climate Dynamics, vol. 42, no. 3-4, pp. 859-877, 2014.

[39] R. A. Potter and M. S. Lozier, "On the warming and salinification of the Mediterranean outflow waters in the North Atlantic," Geophysical Research Letters, vol. 31, no. 1, Article ID L01202, 2004.

[40] M. Borghini, H. Bryden, K. Schroeder, S. Sparnocchia, and A. Vetrano, "The Mediterranean is becoming saltier," Ocean Science, vol. 10, no. 4, pp. 693-700, 2014.

[41] M. Rixen, J.-M. Beckers, S. Levitus et al., "The Western Mediterranean Deep Water: a proxy for climate change," Geophysical Research Letters, vol. 32, no. 12, Article ID L12608, 2005.

[42] S. Hameed, W. Shi, J. Boyle, and B. Santer, Proceedings of the First International AMIP Scientific Conference, vol. 92 of WCRP, World Meteorological Organization, Monterey, Calif, USA, 1995.

[43] K. E. Trenberth and D. A. Paolino Jr., "The Northern Hemisphere sea-level pressure data set: trends, errors and discontinuities," Monthly Weather Review, vol. 108, no. 7, pp. 855-872, 1980.

[44] S. Piontkovski and S. Hameed, "Precursors of copepod abundance in the Gulf of Maine in atmospheric centers of action and sea surface temperature," The Global Atmosphere and Ocean System, vol. 8, no. 4, pp. 283-291, 2002.

[45] L. Yu and R. A. Weller, "Objectively analyzed air-sea heat fluxes for the global ice- free oceans (1981-2005)," Bulletin of the American Meteorological Society, vol. 88, no. 4, pp. 527-539, 2007. 
[46] S. A. Josey, E. C. Kent, and P. K. Taylor, "New insights into the ocean heat budget closure problem from analysis of the SOC air-sea flux climatology," Journal of Climate, vol. 12, no. 9, pp. 2856-2880, 1999.

[47] E. Kalnay, M. Kanamitsu, R. Kistler et al., "The NCEP/NCAR 40-year reanalysis project," Bulletin of the American Meteorological Society, vol. 77, no. 3, pp. 437-471, 1996.

[48] A. Romanou, G. Tselioudis, C. S. Zerefos, C.-A. Clayson, J. A. Curry, and A. Andersson, "Evaporation-precipitation variability over the mediterranean and the black seas from satellite and reanalysis estimates," Journal of Climate, vol. 23, no. 19, pp. 5268-5287, 2010.

[49] A. Mariotti, Y. Pan, N. Zeng, and A. Alessandri, "Long-term climate change in the Mediterranean region in the midst of decadal variability," Climate Dynamics, vol. 44, no. 5-6, pp. 14371456, 2015.

[50] A. Mariotti and A. Dell'Aquila, "Decadal climate variability in the Mediterranean region: roles of large-scale forcings and regional processes," Climate Dynamics, vol. 38, no. 5-6, pp.11291145, 2012.

[51] C. C. Raible, C. Casty, J. Luterbacher et al., "Climate variabilityobservations, reconstructions, and model simulations for the Atlantic-European and Alpine region from 1500-2100 AD," Climatic Change, vol. 79, no. 1-2, pp. 9-29, 2006.

[52] A. Ullmann, B. Fontaine, and P. Roucou, "Euro-Atlantic weather regimes and Mediterranean rainfall patterns: present-day variability and expected changes under CMIP5 projections," International Journal of Climatology, vol. 34, pp. 2634-2650, 2014.

[53] D. M. W. Frierson, "Robust increases in midlatitude static stability in simulations of global warming," Geophysical Research Letters, vol. 33, no. 24, Article ID L24816, 2006.

[54] I. M. Held and B. J. Soden, "Robust responses of the hydrological cycle to global warming," Journal of Climate, vol. 19, no. 21, pp. 5686-5699, 2006.

[55] F. Touratier and C. Goyet, "Impact of the Eastern mediterranean transient on the distribution of anthropogenic $\mathrm{CO}_{2}$ and first estimate of acidification for the Mediterranean Sea," Deep-Sea Research Part I: Oceanographic Research Papers, vol. 58, no. 1, pp. 1-15, 2011.

[56] B. Klein, W. Roether, N. Kress et al., "Accelerated oxygen consumption in eastern Mediterranean deep waters following the recent changes in thermohaline circulation," Journal of Geophysical Research C: Oceans, vol. 108, no. 9, pp. 1-17, 2003. 

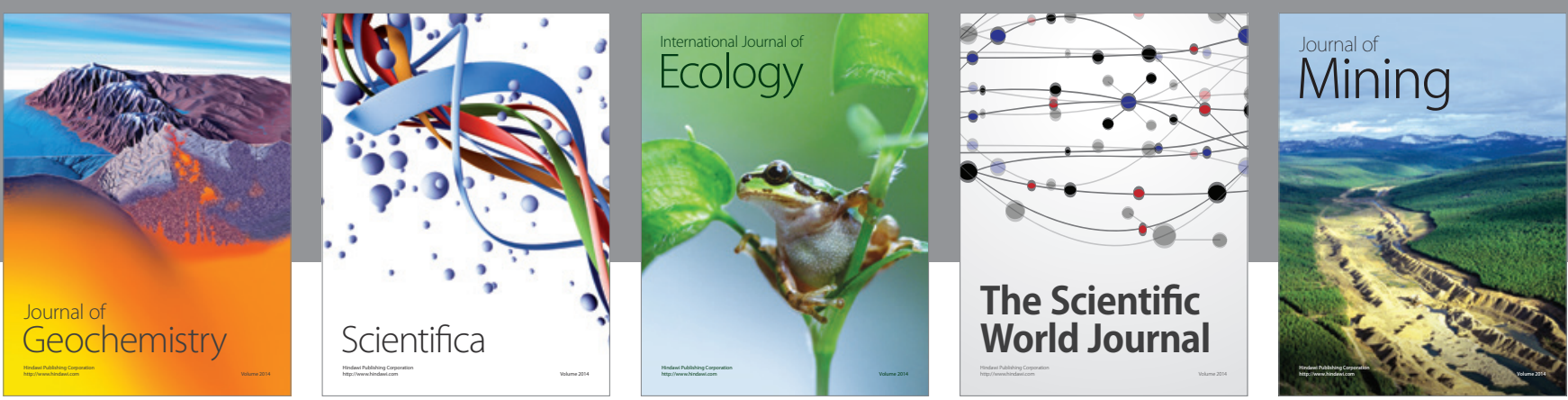

The Scientific World Journal
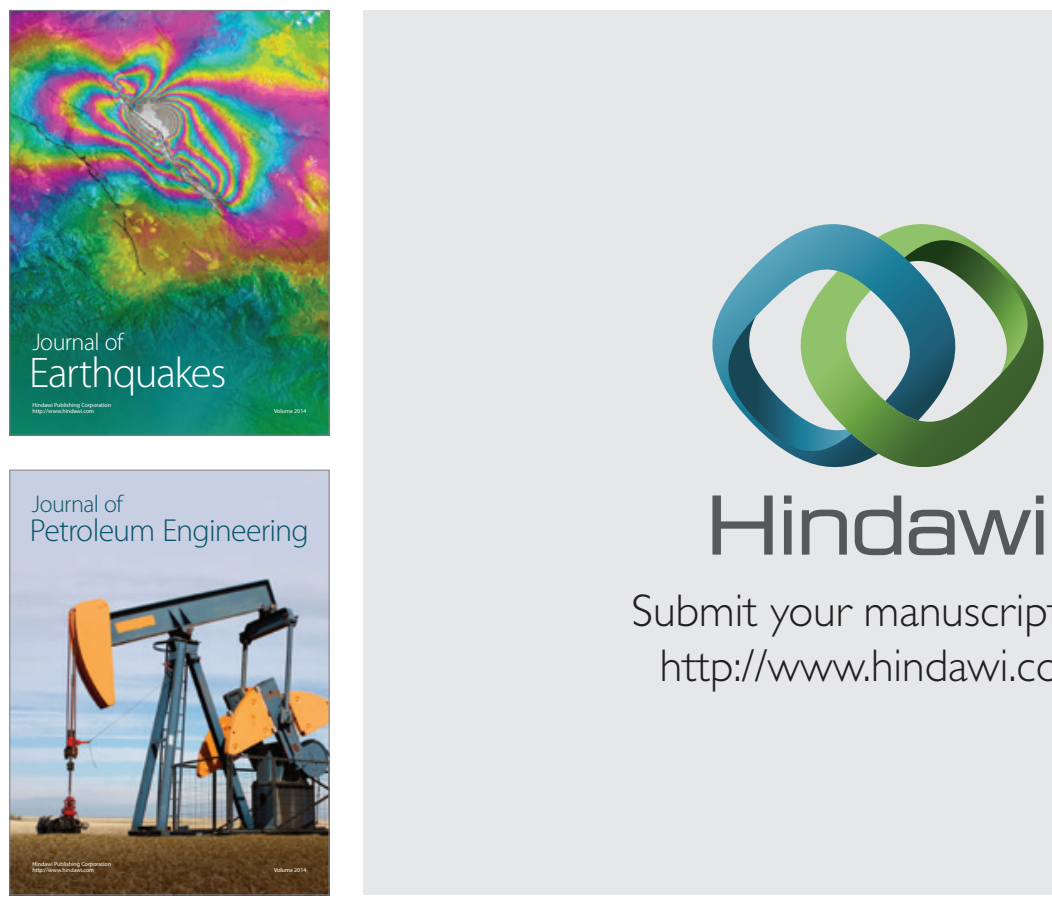

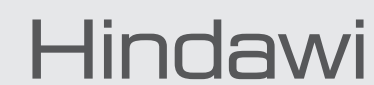

Submit your manuscripts at

http://www.hindawi.com
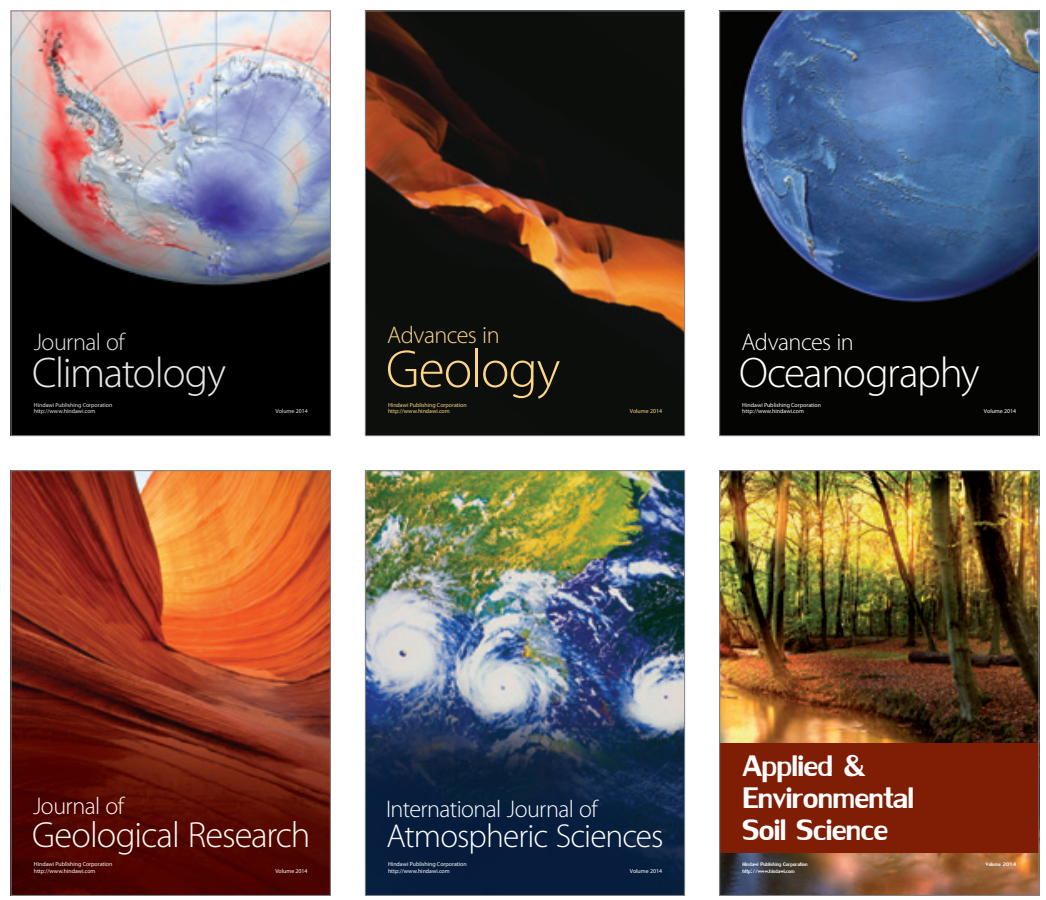
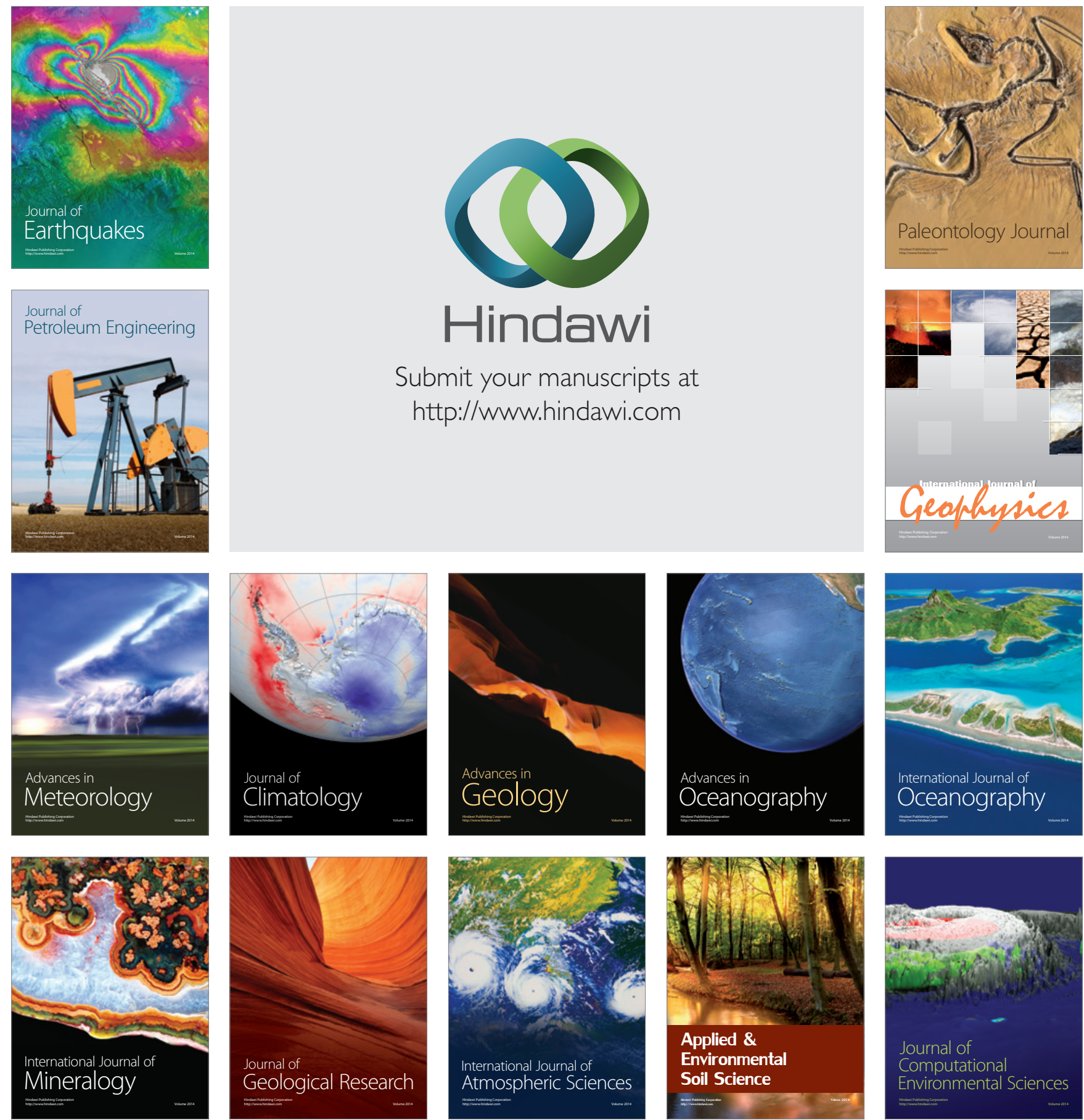